\title{
Titration of Ideal Positive End-expiratory Pressure in Acute Respiratory Distress Syndrome: Comparison between Lower Inflection Point and Esophageal Pressure Method Using Volumetric Capnography
}

\author{
Nandakishore Baikunje, Inderpaul Singh Sehgal, Sahajal Dhooria, Kuruswamy Thurai Prasad, Ritesh Agarwal \\ Department of Pulmonary Medicine, Postgraduate Institute of Medical Education and Research, Chandigarh, India
}

\section{Abstract}

The tenets of mechanical ventilation in acute respiratory distress syndrome (ARDS) include the utilization of low tidal volume and optimal application of positive end-expiratory pressure (PEEP). Optimal PEEP in ARDS is characterized by reduction in alveolar dead space along with improvement in the lung compliance and resultant betterment in oxygenation. There are various methods of setting PEEP in ARDS. Herein, we report a patient of ARDS, wherein we employed measurement of dead space using volumetric capnography to compare two different PEEP strategies, namely, the lower inflection point and transpulmonary pressure monitoring.

Keywords: Acute respiratory distress syndrome, esophageal balloon, lower inflection point, optimal positive end-expiratory pressure, transpulmonary pressure

\section{INTRODUCTION}

Acute respiratory distress syndrome (ARDS) is a syndrome resulting from damage to the alveolocapillary meshwork, ${ }^{[1]}$ characterized by hypoxemic acute respiratory failure and high mortality ranging between $27 \%$ and $45 \% .^{[2]}$ The management principles in ARDS include treatment of the basic inciting condition along with mechanical ventilation and supportive care. Mechanical ventilation not only corrects hypoxemia but also "buys time" for the basic condition to be reversed with specific therapy. Several ventilation strategies have been tried in the management of ARDS, but only a few (low tidal volume strategy and prone-position ventilation) have successfully improved survival in ARDS. Unfortunately, mechanical ventilation, if incorrectly applied can damage the lung per se, the so-called ventilator-associated lung injury (VALI). One important strategy during mechanical ventilation to prevent VALI is avoidance of overdistention and atelectrauma. Ventilating with low tidal volumes easily prevents overdistension. However, one needs to determine the optimal positive end-expiratory pressure (PEEP) to

\begin{tabular}{|l|l|}
\hline \multicolumn{3}{|c|}{ Access this article online } \\
\hline Quick Response Code: & Website: \\
& www.ijccm.org \\
\cline { 2 - 3 } & \\
&
\end{tabular}

prevent atelectrauma. In addition, optimal PEEP also leads to lowest dead space with resultant better lung compliance and oxygenation. ${ }^{[3]}$ Several methods have been used to determine the optimal PEEP in ARDS. Herein, we describe two different strategies of titrating PEEP in a patient of ARDS employing estimation of the lower inflection point (LIP) and esophageal balloon-guided transpulmonary pressure monitoring. We also compare the physiological parameters using the two methods with volumetric capnography.

\section{Case Report}

A 33-year-old pregnant female patient presented with 5 days duration of fever, breathlessness, and productive cough. One

\section{Address for correspondence: Dr. Inderpaul Singh Sehgal, Department of Pulmonary Medicine, Postgraduate Institute of Medical Education and Research, Chandigarh - 160012 , India. E-mail: inderpgi@outlook.com}

This is an open access article distributed under the terms of the Creative Commons Attribution-NonCommercial-ShareAlike 3.0 License, which allows others to remix, tweak, and build upon the work non-commercially, as long as the author is credited and the new creations are licensed under the identical terms.

For reprints contact: reprints@medknow.com

How to cite this article: Baikunje N, Sehgal IS, Dhooria S, Prasad KT, Agarwal R. Titration of ideal positive end-expiratory pressure in acute respiratory distress syndrome: Comparison between lower inflection point and esophageal pressure method using volumetric capnography. Indian J Crit Care Med 2017;21:322-5. 
month before the current illness, she had presented with cough, breathlessness, nasal stuffiness, and decreased hearing. Computed tomography of thorax had revealed bilateral cavitary nodules with areas of consolidation. Antineutrophil cytoplasmic antibody was positive for antiproteinase-3, and a nasal biopsy had demonstrated granulomatous inflammation with necrosis. A diagnosis of granulomatosis with polyangiitis (GPA, previously Wegener's) was made and she was treated with rituximab $\left(375 \mathrm{mg} / \mathrm{m}^{2}\right.$ weekly for 4 weeks) and pulse methylprednisolone $(1 \mathrm{~g}$ intravenous infusion for three consecutive days) followed by oral wysolone $50 \mathrm{mg} /$ day. She responded well to treatment and was discharged with advice to follow up.

Currently, the patient was tachypneic, and arterial blood gases revealed hypoxemia. Blood investigations revealed neutrophilic leukocytosis and hypoalbuminemia [Table 1]. Chest radiograph showed nonhomogenous opacity in the right mid and lower zone and bilateral ground-glass opacity [Figure 1]. A clinical diagnosis of pneumonia in the immunocompromised was made. Due to worsening respiratory failure, she was electively intubated and mechanically ventilated according to the ARDS net protocol (low tidal volume strategy) using the AVEA $^{\mathrm{TM}}$ ventilator (CareFusion, Germany). Cultures from tracheal aspirate and blood demonstrated Methicillin-resistant Staphylococcus aureus. She was started on intravenous vancomycin along with supportive care, stress ulcer, and deep venous thrombosis prophylaxis. To facilitate ventilation, she was sedated and paralyzed (midazolam and pancuronium) during the initial $48 \mathrm{~h}$ of the illness. A LIP corresponding to $6.3 \mathrm{~cm} \mathrm{H}_{2} \mathrm{O}$ was obtained using the pressure-volume (PV) loop. The patient was ventilated with a PEEP of $8 \mathrm{~cm}$ $\mathrm{H}_{2} \mathrm{O}$ ( $2 \mathrm{~cm}$ above LIP), set according to the LIP. Volumetric capnography monitoring was done to calculate dead space ventilation [Table 2]. In brief, ventilator's mainstream $\mathrm{CO}_{2}$ sensor was placed between the ventilator circuit and the patient connection. Exhaled tidal volume and exhaled minute ventilation $\left(\dot{\mathrm{V}}_{\mathrm{E}}\right)$ were measured by the expiratory flow sensor

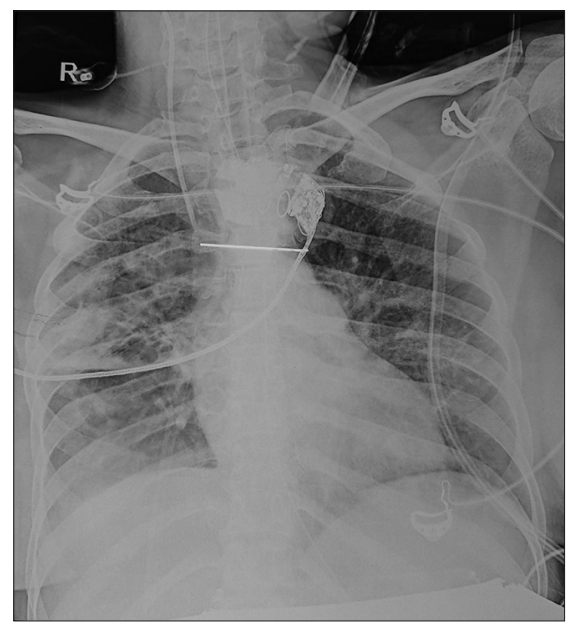

Figure 1: Chest radiograph showing non-homogenous opacity in the right mid and lower zone with bilateral ground-glass opacification of the ventilator. After the measured values of the volumetric $\mathrm{CO}_{2}$ had stabilized and reached a steady state, the amount of $\mathrm{CO}_{2}$ eliminated per breath and minute $\left(\dot{\mathrm{V}}_{\mathrm{CO} 2}\right)$ were measured and averaged over $6 \mathrm{~min}$. The fraction of exhaled $\mathrm{CO}_{2}\left(\mathrm{~F}_{\mathrm{ECO} 2}\right)$ was manually calculated $\left(\dot{\mathrm{V}}_{\mathrm{CO} 2} / \dot{\mathrm{V}}_{\mathrm{E}}\right)$. The partial pressure of mean expired $\mathrm{CO}_{2}\left(\mathrm{P}_{\mathrm{ECO} 2}\right)$ was calculated using the formula $\mathrm{F}_{\mathrm{ECO} 2} \times(747-47)$ (barometric pressure minus water vapor pressure). The alveolar $\mathrm{CO}_{2}$ pressure $\left(\mathrm{PA}_{\mathrm{CO} 2}\right)$ was calculated from the midpoint of Phase II of volumetric capnogram. Both the Bohr's $\left(\mathrm{Vd} / \mathrm{Vt}=\left[\mathrm{P}_{\mathrm{ACO} 2}-\mathrm{P}_{\mathrm{ECO} 2}\right] / \mathrm{P}_{\mathrm{ACO} 2}\right)$ and the Enghoff's $\left(\mathrm{Vd} / \mathrm{Vt}=\left[\mathrm{Pa}_{\mathrm{CO} 2}-\mathrm{P}_{\mathrm{ECO} 2}\right] / \mathrm{Pa}_{\mathrm{CO} 2}\right)$ dead spaces were calculated, where $\mathrm{PA}_{\mathrm{CO} 2}$ is alveolar $\mathrm{PCO}_{2}$, and $\mathrm{P}_{\mathrm{ECO} 2}$ is mixed expired $\mathrm{PCO}_{2}$, and $\mathrm{Pa}_{\mathrm{CO} 2}$ is the arterial $\mathrm{CO}_{2}{ }^{[4]}$ To enable measurement of transpulmonary pressure, a special nasogastric tube with an esophageal catheter (mounted with a $10 \mathrm{~cm}$ long esophageal balloon to measure esophageal pressure) was inserted through the nasal route as previously described. ${ }^{[1]}$ The transpulmonary and esophageal pressures were recorded by giving a $5 \mathrm{~s}$ hold at the end-inspiration and end-expiration, respectively. At a PEEP of $8 \mathrm{~cm} \mathrm{H}_{2} \mathrm{O}$ (using the LIP method), the end-expiratory transpulmonary pressure (Ptp PEEP) was $-6 \mathrm{~cm} \mathrm{H}_{2} \mathrm{O}$, suggesting inappropriate PEEP that would be causing cyclical opening and closing of the alveoli, thus promoting atelectrauma. The PEEP was gradually increased to $12 \mathrm{~cm} \mathrm{H}_{2} \mathrm{O}$ to maintain an end-inspiratory transpulmonary pressure (Ptp plat) of $13 \mathrm{~cm} \mathrm{H}_{2} \mathrm{O}$ and Ptp PEEP of $2 \mathrm{~cm}$ $\mathrm{H}_{2} \mathrm{O}$, in agreement with standard ventilatory strategies using esophageal pressure measurement. ${ }^{[5]}$ Dead space was again estimated using volumetric capnography and arterial blood gas analysis [Table 2].

There was a reduction in both the alveolar and physiological dead space fraction when the PEEP was set at a level of $12 \mathrm{~cm} \mathrm{H}_{2} \mathrm{O}$ [Table 2]. There was also improvement in the respiratory system compliance (Crs) from $18.7 \mathrm{~cm}$ to $23 \mathrm{~cm}$ $\mathrm{H}_{2} \mathrm{O}$. Over the next 1 week, her clinical condition showed

\begin{tabular}{lc}
\hline Table 1: Baseline investigations of the patient & \\
\hline Parameter & Value \\
\hline Hemoglobin (g/dL) & 10.5 \\
Total leukocyte count (cells/ $\mathrm{L}$ ) & 20,600 \\
Platelet count (cells/ $\mu \mathrm{L})$ & 152,000 \\
Blood urea (mg/dL) & 22 \\
Serum creatinine (mg/dL) & 0.46 \\
Calcium (mg/dL) & 7.7 \\
Phosphorus (mg/dL) & 4.4 \\
Protein (g/dL) & 5.0 \\
Albumin (g/dL) & 2.33 \\
Serum bilirubin (mg/dL) & 1.85 \\
Aspartate transaminase (U/L) & 33 \\
Alanine transaminase (U/L) & 35 \\
Alkaline phosphatase (U/L) & 122 \\
Magnesium (mg/dL) & 2.04 \\
Blood culture & S. aureus \\
Endotracheal aspirate culture & S. aureus \\
\hline S. aureus: Staphylococcus aureus &
\end{tabular}




\begin{tabular}{|c|c|c|}
\hline & Using LIP & $\begin{array}{l}\text { Using transpulmonary } \\
\text { pressure }\end{array}$ \\
\hline Tidal volume (mL) & 300 & 300 \\
\hline Respiratory rate (breaths/min) & 28 & 28 \\
\hline $\operatorname{PEEP}\left(\mathrm{cm} \mathrm{H}_{2} \mathrm{O}\right)$ & 8 & 12 \\
\hline $\mathrm{FiO}_{2}$ & 0.5 & 0.5 \\
\hline Peak flow (L/min) & 65 & 65 \\
\hline Minute volume (L) & 8.4 & 8.4 \\
\hline Peak pressure $\left(\mathrm{cm} \mathrm{H}_{2} \mathrm{O}\right)$ & 31 & 33 \\
\hline Plateau pressure $\left(\mathrm{cm} \mathrm{H}_{2} \mathrm{O}\right)$ & 24 & 27 \\
\hline Ptp Plat $\left(\mathrm{cm} \mathrm{H}_{2} \mathrm{O}\right)$ & 8 & 13 \\
\hline Ptp PEEP $\left(\mathrm{cm} \mathrm{H}_{2} \mathrm{O}\right)$ & -6 & 2 \\
\hline $\mathrm{Crs}\left(\mathrm{mL} / \mathrm{cm} \mathrm{H}_{2} \mathrm{O}\right)$ & 18.7 & 23 \\
\hline $\mathrm{EtCO}_{2}(\mathrm{mmHg})$ & 27.7 & 27.6 \\
\hline $\mathrm{PaCO}_{2}$ in alveoli (mmHg) & 26.7 & 28.0 \\
\hline $\mathrm{PaO}_{2}$ in arterial blood $(\mathrm{mmHg})$ & 112 & 118.7 \\
\hline $\mathrm{PaCO}_{2}$ in arterial blood $(\mathrm{mmHg})$ & 28.5 & 36.5 \\
\hline $\mathrm{VCO}_{2}$ expired $(\mathrm{mL} / \mathrm{min})$ & 126 & 158 \\
\hline $\mathrm{VA}(\mathrm{L} / \mathrm{min})$ & 3.14 & 3.17 \\
\hline $\mathrm{PeCO}_{2}(\mathrm{mmHg})$ & 9.38 & 13.33 \\
\hline $\mathrm{PaO}_{2} / \mathrm{FiO}_{2}$ ratio & 261 & 277 \\
\hline $\mathrm{Vd}$ alv $(\mathrm{mL})$ & 142 & 123 \\
\hline Vd phys (mL) & 199 & 154 \\
\hline $\begin{array}{l}\text { Ratio of dead space to tidal } \\
\text { volume (Vd/Vt) (Enghoff) (\%) }\end{array}$ & 67.08 & 63.47 \\
\hline $\begin{array}{l}\text { Ratio of dead space to tidal } \\
\text { volume (Vd/Vt) (Bohr) (\%) }\end{array}$ & 64.86 & 52.39 \\
\hline
\end{tabular}

LIP: Lower inflection point; PEEP: Positive end-expiratory pressure; $\mathrm{FiO}_{2}$ : Fraction of inspired oxygen; Crs: Respiratory system compliance; $\mathrm{EtCO}_{2}$ : End-tidal carbon dioxide; $\mathrm{VCO}_{2}$ : Volume of $\mathrm{CO}_{2}$; VA: Alveolar ventilation; $\mathrm{PaCO}_{2}$ : Partial pressure of $\mathrm{CO}_{2} ; \mathrm{PaO}_{2}$ : Partial pressure of $\mathrm{O}_{2}$ in arterial blood; Vd alv: Alveolar dead space; Vd phys: Physiological dead space; $\mathrm{PECO}_{2}$ : Mixed expired $\mathrm{CO}_{2}$ pressure; Ptp Plat: Transpulmonary end-inspiratory pressure; Ptp PEEP: Transpulmonary end-expiratory pressure

gradual improvement, and she was extubated after 10 days of mechanical ventilation. At 4-week follow-up, the patient is in a stable condition not requiring oxygen and can carry out her activity of daily living independently.

\section{Discussion}

The index case highlights the utility of transpulmonary pressure monitoring (estimated by esophageal balloon) in setting the optimal PEEP in ARDS. The use of optimal PEEP was associated with a lesser fraction of dead space ventilation. In contrast, the use of the PV curve-guided LIP resulted in underestimation of PEEP and a higher dead space ventilation.

PEEP is an important component in the management of ARDS. PEEP improves hypoxemia by recruiting the collapsed alveoli thereby reducing intrapulmonary shunting. However, inappropriately high levels of PEEP may cause overdistension of the alveoli, thus causing baro- and volu-trauma, whereas inadequate PEEP can result in atelectrauma due to repeated opening and closing of the alveoli. Thus, it is prudent to set an optimal PEEP. It has been previously shown that there is a marked variation in the pleural and abdominal pressures among critically ill patients and that the amount of PEEP needed to recruit the alveoli may vary on a patient-to-patient basis. ${ }^{[5,6]}$ One method of setting PEEP is using the LIP obtained by a PV curve. In two studies comparing PV curve-based strategy (to set PEEP) and low tidal volume versus a high tidal volume and low PEEP strategy, there was a significant improvement in the survival in the low tidal volume group. ${ }^{[7,8]}$ However, it was not clear whether the benefit was solely because of a low tidal volume strategy or an optimal level of PEEP. ${ }^{[7,8]}$ In later studies comparing a high PEEP versus a low PEEP strategy, there was a significantly better oxygenation in the high PEEP arm, but there was no benefit in the survival..$^{[9,10]}$ However, in these studies, PEEP was set arbitrarily based on the $\mathrm{FI}_{\mathrm{O} 2}$ requirement and not according to the lung mechanics of an individual patient. ${ }^{[9,10]}$ Thus, it is possible that the benefits of high PEEP for some might have been offset by harm to others due to overdistention of the alveoli. This fact is further supported by a computed tomography-based study where the response to PEEP in patients with ARDS was found to be variable and dependent on the amount of recruitable lungs. ${ }^{[11]}$ Another method of setting PEEP is by measuring transpulmonary pressure monitoring using an esophageal balloon. ${ }^{[5]}$ This strategy resulted in significant improvement in the oxygenation parameters in the transpulmonary pressure group with a trend toward a better survival. ${ }^{[5]}$ The use of transpulmonary pressures can help in compartmentalization of the respiratory system mechanics (chest wall and respiratory system compliance) and helps in setting an appropriate PEEP. ${ }^{[1]}$ At a PEEP of $8 \mathrm{~cm} \mathrm{H}_{2} \mathrm{O}$ (LIP-based strategy), the Ptp PEEP was negative suggesting that there was ongoing alveolar collapse at the end-expiration. The utilization of transpulmonary pressure-guided PEEP resulted in an increase in the PEEP from $8 \mathrm{~cm}$ to $12 \mathrm{~cm} \mathrm{H}_{2} \mathrm{O}$. This not only avoided end-expiratory alveolar collapse (Ptp PEEP $>0 \mathrm{~cm} \mathrm{H}_{2} \mathrm{O}$ ) but also caused a reduction in the dead space fraction. Overdistension of the alveoli was avoided by maintaining the end-inspiratory transpulmonary pressure below $25 \mathrm{~cm} \mathrm{H}_{2} \mathrm{O}$.

The use of volumetric capnography (a noninvasive technique) helped us in calculating the alveolar and airway dead space. ${ }^{[12]}$ Monitoring of dead space by volumetric capnography also aids in setting optimal PEEP. ${ }^{[13,14]}$ This was shown in a study where the "best PEEP" coincided with best pulmonary compliance, which also coincided with lowest Enghoff physiological dead space and maximum oxygen transport. ${ }^{[3,15]}$ Even in the index case, we noticed a reduction in physiological dead space along with the improvement of oxygenation and respiratory mechanics when PEEP level was set according to esophageal pressure measurement as compared to setting PEEP according to LIP.

\section{Conclusion}

This single-case observation points toward the benefit of setting PEEP using a transpulmonary pressure-guided strategy 
when compared to LIP-based strategy. There was reduction in both the alveolar and physiologic dead space measured by volumetric capnography possibly due to opening up of more collapsed alveoli.

\section{Financial support and sponsorship}

Nil.

\section{Conflicts of interest}

There are no conflicts of interest.

\section{RefEREnCES}

1. Sehgal IS, Dhooria S, Behera D, Agarwal R. Acute respiratory distress syndrome: Pulmonary and extrapulmonary not so similar. Indian J Crit Care Med 2016;20:194-7.

2. Sehgal IS, Agarwal R. Non-invasive ventilation in acute respiratory distress syndrome: Helmet use saves lives? Ann Transl Med 2016;4:349.

3. Suter PM, Fairley B, Isenberg MD. Optimum end-expiratory airway pressure in patients with acute pulmonary failure. N Engl J Med 1975;292:284-9.

4. Verscheure S, Massion PB, Verschuren F, Damas P, Magder S. Volumetric capnography: Lessons from the past and current clinical applications. Crit Care 2016;20:184.

5. Talmor D, Sarge T, Malhotra A, O'Donnell CR, Ritz R, Lisbon A, et al. Mechanical ventilation guided by esophageal pressure in acute lung injury. N Engl J Med 2008;359:2095-104.

6. Talmor D, Sarge T, O’Donnell CR, Ritz R, Malhotra A, Lisbon A, et al. Esophageal and transpulmonary pressures in acute respiratory failure. Crit Care Med 2006;34:1389-94.
7. Amato MB, Barbas CS, Medeiros DM, Magaldi RB, Schettino GP, Lorenzi-Filho G, et al. Effect of a protective-ventilation strategy on mortality in the acute respiratory distress syndrome. N Engl J Med 1998;338:347-54.

8. Villar J, Kacmarek RM, Pérez-Méndez L, Aguirre-Jaime A. A high positive end-expiratory pressure, low tidal volume ventilatory strategy improves outcome in persistent acute respiratory distress syndrome: A randomized, controlled trial. Crit Care Med 2006;34:1311-8.

9. Brower RG, Lanken PN, MacIntyre N, Matthay MA, Morris A, Ancukiewicz M, et al. Higher versus lower positive end-expiratory pressures in patients with the acute respiratory distress syndrome. N Engl J Med 2004;351:327-36.

10. Meade MO, Cook DJ, Guyatt GH, Slutsky AS, Arabi YM, Cooper DJ, et al. Ventilation strategy using low tidal volumes, recruitment maneuvers, and high positive end-expiratory pressure for acute lung injury and acute respiratory distress syndrome: A randomized controlled trial. JAMA 2008;299:637-45.

11. Gattinoni L, Caironi P, Cressoni M, Chiumello D, Ranieri VM, Quintel M, et al. Lung recruitment in patients with the acute respiratory distress syndrome. N Engl J Med 2006;354:1775-86.

12. Suarez-Sipmann F, Bohm SH, Tusman G. Volumetric capnography: The time has come. Curr Opin Crit Care 2014;20:333-9.

13. Tusman G, Groisman I, Fiolo FE, Scandurra A, Arca JM, Krumrick G, et al. Noninvasive monitoring of lung recruitment maneuvers in morbidly obese patients: The role of pulse oximetry and volumetric capnography. Anesth Analg 2014;118:137-44.

14. Böhm SH, Maisch S, von Sandersleben A, Thamm O, Passoni I, Martinez Arca J, et al. The effects of lung recruitment on the phase III slope of volumetric capnography in morbidly obese patients. Anesth Analg 2009;109:151-9.

15. Fengmei G, Jin C, Songqiao L, Congshan Y, Yi Y. Dead space fraction changes during PEEP titration following lung recruitment in patients with ARDS. Respir Care 2012;57:1578-85. 